DOI: 10.47456/krkr.v1i5.32642

\title{
A formação inicial de professores e as conquistas do PIBID
}

Initial teacher education and the PIBID's achievements Elizabeth Magalhães de Oliveira

Elisabeth dos Santos Tavares

Lais Helena Teixeira Merlin de Andrade

Resumo: Por meio do PIBID, Programa Institucional de Bolsa de Iniciação à Docência, concedido pela CAPES, foi possível desenvolver o Subprojeto Pedagogia "Articulação das linguagens: literatura, arte, matemática e ciências", na Universidade Metropolitana de Santos (UNIMES). Este projeto foi ancorado em abordagens interdisciplinar e multidisciplinar, conforme propostas nos Parâmetros Curriculares Nacionais (PCN), na BNCC (Base Nacional Comum Curricular), no PNAIC (Plano Nacional de Alfabetização na Idade Certa), e, ainda propôs que as atividades a serem desenvolvidas no ambiente escolar devem considerar as especificidades de cada uma das práticas de linguagem em função da articulação que estabelecem entre si. Este artigo apresenta relatos de experiências vivenciadas pelos bolsistas, alunos de Licenciatura em Pedagogia, durante a aplicação de atividades no ambiente escolar. Buscou-se favorecer a mobilização dos educandos da EMEF Prefeito Jonas Rodrigues, lotada no município de São Vicente (SP), para a aprendizagem frente ao aspecto lúdico presente no ler e contar histórias, potencializando o processo de ensino-aprendizagem e, promovendo o contato com áreas do conhecimento diversas. Para os licenciandos, a participação no projeto contribuiu para a articulação entre teoria e prática necessária à formação docente, elevando a qualidade das ações acadêmicas. Desta forma, na interação, na discussão e na socialização, puderam reconhecer a importância e a responsabilidade do papel de futuro professor.

Palavras-Chave: PIBID/CAPES. Interdisciplinaridade. Multidisciplinaridade. Articulação de linguagens. Relatos de experiências.

Abstract: Through the "Programa Institucional de Bolsa de Iniciação à Docência" (Institutional Teaching Initiation Scholarship Program - PIBID), granted by "Coordenação de Aperfeiçoamento de Pessoal de Nível Superior" (Coordination for the Improvement of Higher Education Personnel - CAPES), it was possible to develop the pedagogy subproject "Articulation of languages: literature, art, mathematics and science", at the Metropolitan University of Santos (UNIMES). This project was anchored in interdisciplinary and multidisciplinary approaches, as proposed in the "Parâmetros Curriculares Nacionais" (National Curriculum Parameters - PCN), in the "Base Nacional Comum Curricular" (Common National Curriculum Base - BNCC), in the "Plano Nacional de Alfabetização na Idade Certa" (National Literacy Plan at the Right Age - PNAIC), and further proposed that the activities to be developed in the school environment must consider the specificities of each language practice in function of the articulation that they establish among themselves. This article presents reports of experiences lived by scholarship students, undergraduate students in Pedagogy, during the application of activities in the school environment. The mobilization of students from EMEF Mayor Jonas Rodrigues was favored, based in the city of São Vicente (SP), for learning in the face of the playful aspect of reading and telling stories, enhancing the teaching-learning process and promoting contact with 
diverse areas of knowledge. For graduates, the participation in the project contributed to the articulation between theory and practice necessary for teacher training, raising the quality of academic actions. Thus, during the interaction, discussion and socialization, they were able to recognize the importance and responsibility of the role of future teacher.

Keywords: PIBID/CAPES. Interdisciplinary. Multidisciplinary. Articulation of languages. Reports of experiences.

\section{Introdução}

O Programa Institucional de Bolsa de Iniciação à Docência - PIBID, sob a coordenação da Coordenação de Aperfeiçoamento de Pessoal de Nível Superior (CAPES), por meio de sua Diretoria de Formação de Professores da Educação Básica (DEB) seleciona instituições de ensino superior (IES) para desenvolverem projetos de iniciação à docência nos cursos de licenciatura em regime de colaboração com as redes de ensino. Os públicos alvos do PIBID são discentes que estejam na primeira metade de curso de licenciatura ofertado por IES pública ou privada sem fins lucrativos, na modalidade presencial ou no âmbito do Sistema Universidade Aberta do Brasil (UAB).

A Universidade Metropolitana de Santos - UNIMES, ao longo de sua trajetória histórica de mais de 50 anos, sempre esteve atenta a melhoria da qualidade de vida da comunidade regional, com uma contribuição relevante em relação à formação de seus alunos, às pesquisas desenvolvidas e atividades de extensão que visam à formação integral do indivíduo, o desenvolvimento de seu senso crítico, ético e capacidade de agir diante dos desafios que são colocados pela sociedade contemporânea.

Busca-se assim, contribuir para o desenvolvimento da dignidade humana, por meio do ensino e dos serviços prestados à comunidade.

A UNIMES sempre se destacou pelos cursos de licenciatura, tendo iniciado suas atividades em 20 de junho de 1968 quando foi criada a sua primeira faculdade - Faculdade de Educação Física. Ao longo dos anos, outros cursos de licenciatura foram sendo instalados. Em 2006 foi credenciada para atuar na modalidade de Educação a Distância (EaD), quando foram implementados novos cursos voltados especialmente à formação de docentes, mantendo-se os cursos de licenciatura presenciais, também. Complementando a formação docente tem garantido a formação em nível de pós-graduação Latu 
sensu por meio de cursos especialmente voltados à ampliação da formação dos professores e, ainda Stricto sensu com um mestrado profissional, dentre outros, na área do ensino com discentes na sua maioria oriunda da rede pública de ensino.

A universidade está localizada na cidade de Santos, no Estado de São Paulo e tem sua área de abrangência geográfica envolvendo a Região Metropolitana da Baixada Santista, criada em 1996, que abrange nove municípios, dentre eles Santos.

Dentre os objetivos do PIBID estão incentivar a formação de docentes em nível superior para a educação básica; contribuir para a valorização do magistério; elevar a qualidade da formação inicial de professores nos cursos de licenciatura, promovendo a integração entre educação superior e educação básica; inserir os licenciandos no cotidiano de escolas da rede pública de educação, proporcionando-Ihes oportunidades de criação e participação em experiências metodológicas, tecnológicas e práticas docentes de caráter inovador e interdisciplinar que busquem a superação de problemas identificados no processo de ensino e de aprendizagem; incentivar escolas públicas de educação básica, mobilizando seus professores como coformadores dos futuros docentes e tornando-as protagonistas nos processos de formação inicial para o magistério e contribuir para a articulação entre teoria e prática necessárias à formação dos docentes, elevando a qualidade das ações acadêmicas nos cursos de licenciatura.

A opção pela submissão de dois subprojetos à CAPES deveu-se a crença na possibilidade de se oferecer formação complementar aos alunos dos cursos de licenciatura e também de se estabelecer uma articulação com os professores em exercício em escolas públicas da região.

\section{O Subprojeto Pedagogia Articulação das linguagens - literatura, arte, matemática e ciências}

Um dos subprojetos, relacionado ao curso de Licenciatura em Pedagogia, "Articulação das linguagens - literatura, arte, matemática e ciências" foi desenvolvido em uma escola do município de São Vicente (SP), 
município que possui uma grande rede do Ensino Fundamental dos anos iniciais. Por meio do subprojeto objetivou-se refletir e exercitar sobre as diversas abordagens de letramentos e linguagens que possibilitam novas aprendizagens na escola com a indicação de vários caminhos para a formação docente.

Este subprojeto de Pedagogia foi ancorado na abordagem interdisciplinar e multidisciplinar, em que as atividades propostas no ambiente escolar consideraram as especificidades de cada uma das práticas de linguagem em função da articulação que estabelecem entre si. Nesse sentido, o que se cultivou foi a prática efetiva da leitura, considerando a diversidade de gêneros, e a atuação em atividades externas à sala de aula, a fim de possibilitar que o aluno ultrapassasse a barreira do não ler para o ler, e produzisse textos, se expressasse de diferentes formas por meio de gêneros textuais diversos.

A UNIMES, desde o início das atividades do subprojeto, em um desafio, debateu com sua equipe instrumentos de gestão, acompanhamento e avaliação adequados à realidade da Universidade, o que imprimiu uma dinâmica própria e diferenciada para o subprojeto.

O município de São Vicente é um dos nove municípios da Região Metropolitana da Baixada Santista que se caracteriza pela grande diversidade de funções presentes nos municípios que a compõem apresentando problemas comuns aos grandes aglomerados urbanos, como os relacionados com a questão ambiental, carência de infraestrutura, saneamento ambiental, transporte e habitação. São Vicente privilegia-se de localização, pois atende tanto à demanda dos munícipes situados na área insular, quanto da área continental através da Ponte dos Barreiros como, ainda, de quem desce a serra para acessar ao município de Santos na parte da zona noroeste e de outro às praias e proximidades na zona leste ou, por fim, como acesso ao município de Praia Grande pela Ponte Pênsil. 


\section{O PIBID na Escola Jonas Rodrigues}

A Escola Municipal Jonas Rodrigues está localizada em um bairro com adensamento de moradores, tem interligação com o centro da cidade e possui alguns problemas visíveis como pontos de descarte inadequado de lixo. Em período de chuvas ocorrem enchentes constantes inclusive em alguns pontos da escola, como salas de aula. No entanto, estas características mencionadas não atrapalharam o desenvolvimento do subprojeto PIBID/UNIMES.

A escola atende a alunos do Ensino Fundamental I, EJA e Educação Infantil. É uma dependência Municipal situada na Rua Alexandre Sendim, 304 no Bairro Parque Bitaru, em São Vicente.

\section{Expectativas dos gestores e professores}

Em reunião realizada na escola foi apresentada uma sugestão pelos membros da Secretaria Municipal de Educação de São Vicente de que o projeto fosse inteiramente desenvolvido na Escola Prefeito Jonas Rodrigues, tendo em vista o grande número de alunos, total aproximado de 600 alunos e considerando ainda os períodos de atendimento da escola: matutino e tarde, desta forma a Universidade acatou as expectativas dos gestores presentes na reunião e desenvolveu três turmas na própria escola.

Outra expectativa revelada e demonstrada se deu em relação às observações do ambiente de alegria que permeou o processo da construção do conhecimento pelas crianças e o trabalho do professor. Os gestores esperavam que esse clima trazido pela Universidade contaminasse ainda mais o ambiente escolar. A imersão dos alunos da licenciatura, na unidade escolar, se deu por meio de orientação de uma postura que refletisse uma relação de respeito, colaboração e diálogo permanente com a equipe gestora da escola e com o professor supervisor, visando à construção de uma relação positiva entre discente bolsista - aluno pesquisador e supervisor professor.

Os recursos metodológicos diversos também foram objetos de apreciação pelos professores presentes, que demonstraram interesse no uso de novas metodologias que despertassem interesse dos alunos em aprender. Desta forma se pretendeu que os discentes bolsistas desenvolvessem uma 
postura investigativa valorizando a atividade docente em uma articulação entre teoria e prática visando não somente a melhoria do seu rendimento acadêmico na universidade, mas também a vivência de metodologias inovadoras.

$\mathrm{Na}$ escola, o objetivo maior foi a melhoria da qualidade do processo de ensino e de aprendizagem, que as crianças pudessem utilizar a linguagem na escuta e produção de textos orais e na leitura e produção de textos escritos nas diferentes áreas do conhecimento identificando aspectos relevantes do conhecimento.

\section{Planejamento, organização e execução das atividades: experiências significativas}

O subprojeto PIBID proposto aos alunos bolsistas da licenciatura em pedagogia da Universidade Metropolitana de Santos (UNIMES) buscou cumprir seus objetivos por meio da integração entre a literatura infanto-juvenil, Artes, Matemática e Ciências e de atividades aplicadas em sala de aula visando o favorecimento da mobilização destes licenciandos para a aprendizagem frente ao aspecto lúdico presente no ler e contar histórias, para potencializar as aprendizagens e promover o contato com áreas do conhecimento diversas.

As habilidades pretendidas envolveram alguns componentes curriculares: língua portuguesa (leitura, oralidade, argumentação, registroprodução de diferentes gêneros); matemática (números e operações contagem, ordenação); ciências (características de alguns animais - peso, altura, tempo de gestação, tempo de vida); arte (desenvolvimento de habilidades importantes para todas as áreas de conhecimento - escuta atenta e capaz de distinguir diferentes sons do ambiente, necessária à realização de trabalhos coletivos; noções de lateralidade, coordenação motora, atenção e percepção de si e do outro, além da sensibilidade para o ambiente sonoro e superação de posturas que impedem comunicação e convívio respeitoso).

Ao longo do desenvolvimento deste subprojeto, entre 2018 e 2019, foi verificada a evolução dos licenciandos e a aquisição de maturidade no processo de formação docente. A cada nova etapa, os alunos se apropriavam dos novos conhecimentos e encaravam os desafios buscando sempre o 
aprimoramento, a superação das dificuldades encontradas e aprendizados significativos.

Este subprojeto foi dividido em blocos de atividades visando o cumprimento dos objetivos delineados e o desenvolvimento de múltiplas habilidades. Dentre as propostas foram desenvolvidas atividades temáticas como "o circo" para despertar do imaginário dos aprendizes, de modo a trabalhar diferentes linguagens como, a corporal, a musical, a plástica, e a oral; buscando a promoção de experiências significativas de aprendizagem, enfatizando aspectos culturais e a importância do respeito e cuidado para com o próximo.

Adicionalmente, foram propostas atividades pedagógicas por meio de diferentes jogos como uma forma de tornar o processo ensino-aprendizagem mais interessante, agradável, significativo e colaborativo.

Outra etapa realizada com os alunos foi a proposição de atividades voltadas para o comportamento de diferentes organismos vivos, o ambiente e a sustentabilidade, visando o despertar, o pertencimento, o cuidar, a sensibilização e a conscientização dos educandos e de todos os envolvidos.

\section{O Circo}

No primeiro semestre de 2019 , foi desenvolvido o trabalho temático "O Circo" que propôs, primeiramente, a pesquisa sobre a história do tema, os personagens artísticos mais marcantes atuantes em circos e a importância cultural desta atuação. Alguns licenciandos/bolsistas PIBID relataram as suas pesquisas.

\footnotetext{
"A história do Circo no Brasil começa no século XIX com famílias e companhias vindas da Europa, onde agruparam-se em guetos e manifestavam sentimentos diversos através de interpretações teatrais onde não demonstravam apenas interesses individuais e sim despertavam consciência mútua [...] sempre houve ligação dos ciganos com o circo". Entre suas especialidades incluíam-se a doma de ursos, o ilusionismo e as exibições com cavalos. Há relatos de que eles usavam tendas e nas festas sacras, havia bagunça, bebedeira, e exibições artísticas, incluindo teatro de bonecos" (Relato da licencianda em pedagogia Cynthia Gonçalves Matos Nunes).
} 
No decorrer desta etapa do projeto, tanto os alunos da escola, como os bolsistas, deveriam fazer narrativas para trabalhar o letramento e oralidade, expor valores importantes para a vida, como a união, a alegria, a solidariedade, a justiça e a diversidade.

A escolha do filme "Os Saltimbancos Trapalhões" uma releitura do musical dos irmãos Grimm, trazido para o Brasil por Chico Buarque, proporcionou a preparação dos alunos da escola com a orientação dos bolsistas e coordenadoras, que trabalharam a arte, a expressão corporal, a linguagem, a dança e produziram uma apresentação surpreendente dos envolvidos neste projeto. Foi realizada pelas crianças a apresentação e releitura do espetáculo mencionado e, a interpretação das músicas "História de Uma Gata" e "Piruetas" (figura 1). Resultados positivos com a execução desta experiência foram relatados pelos licenciandos.

"O projeto Circo consolidou resultados interessantes, a participação de todos foi muito gratificante; os alunos demonstraram muito interesse por atividades envolvendo a arte e sempre queriam aprimorar a atividade imposta; desenvolveram em muitos aspectos e manifestaram diversas percepções. Foi desenvolvido nos alunos o gosto pela arte e, nos estudantes de pedagogia, o gosto pela contribuição no aprendizado e desenvolvimento das crianças. Mergulhamos no mundo da imaginação e fantasia" (Relato da licencianda em pedagogia Patrícia Generozo Pataro Tavares).

Figura 1. Organização e apresentação da atividade "O Circo"1
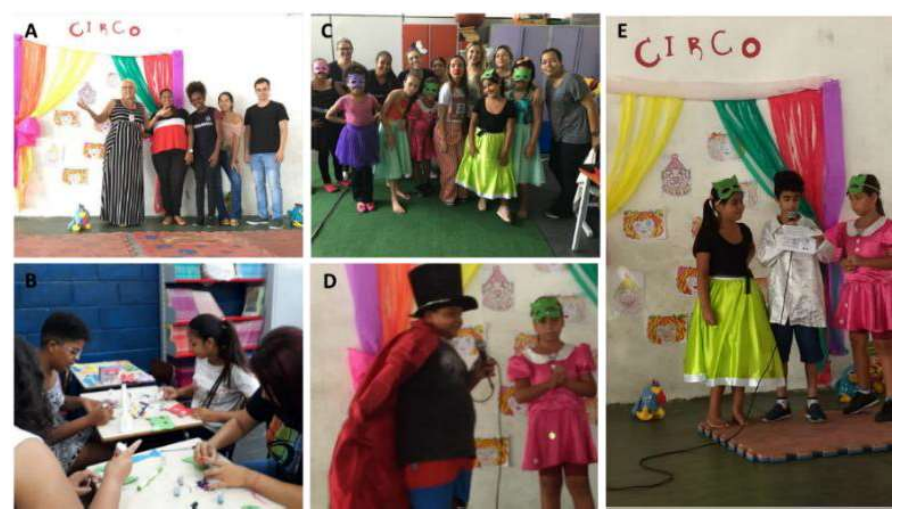

Fonte: Autoria própria*

\footnotetext{
1 A. Coordenadora de área e licenciados preparando o cenário; B. Alunos PIBID confeccionando as máscaras; C. Equipe de alunos PIBID e da escola EMEF Prefeito Jonas Rodrigues; D-E. Interpretação das crianças em dois momentos distintos.

* Crédito aos licenciandos e a coordenadora de área.
} 


\section{Jogos pedagógicos}

No mês de junho de 2019 foi realizada uma oficina de jogos pedagógicos, aplicada pelas professoras supervisoras com auxílio dos bolsistas, aos escolares dos anos iniciais do ensino fundamental, $3^{\circ}, 4^{\circ}$ e $5^{\circ}$ ano, da escola EMEF Prefeito Jonas Rodrigues. A oficina foi preparada e testada previamente pelos bolsistas nas reuniões de formação que aconteceram na IES (UNIMES), onde tiveram a oportunidade de pesquisar, estudar, discutir e refletir sobre a temática, bem como elaborar propostas de jogos, reescrevendo as regras originais para que se tornassem mais acessíveis aos aprendizes.

Durante a elaboração e organização desta atividade, os alunos PIBID significaram estas atividades e demonstraram por meio de relatos.

"O objetivo é demonstrar a importância das atividades lúdicas na alfabetização, visto que jogos e brincadeiras são importantes na construção de uma aprendizagem significativa nos anos iniciais. Pretende-se comprovar que a utilização de jogos e brincadeiras em sala de aula contribui para formação de atitudes sociais como respeito mútuo, cooperação, relação social e interação, auxiliando na construção do conhecimento. Sabe-se que a criança se caracteriza principalmente pela sua criatividade, pelo fascínio das descobertas, das atividades e situações diferentes, enfim, possui extremo interesse pelo novo, pelo palpável e por tudo o que é no concreto. Assim o processo de aprendizagem na alfabetização e letramento torna-se prazeroso, fácil e dinâmico" (Relato da licencianda em pedagogia Julia Marquez Navas Mendes).

As atividades da oficina foram organizadas em estações elaboradas em cada sala de aula de modo que todos os alunos conseguissem experimentar os jogos propostos. Os bolsistas fizeram rodízios com os educandos em cada uma das estações, com tempo controlado. Durante a aplicação dos jogos os alunos demonstraram interesse e envolvimento, sem apresentar dificuldades em relação ao jogar, pois, as informações estavam bem claras e objetivas, descritas em cada regra proposta (Figura 2).

Os jogos não tiveram a intenção de competição, e sim de participação colaborativa entre as crianças, que estavam aprendendo, testando seus conhecimentos brincando. Pois, o objetivo principal desta oficina foi aplicar os jogos na educação, como uma ferramenta complementar ao processo de 
desenvolvimento das crianças. O jogo pode ser considerado importante no que se refere à aquisição de conhecimento e desempenho no âmbito escolar auxiliando na melhora de aspectos cognitivos, sociais, emocionais e físicomotores.

Figura 2. Aplicação dos jogos pedagógicos nas turmas de terceiro ao quinto ano do ensino fundamental ${ }^{2}$

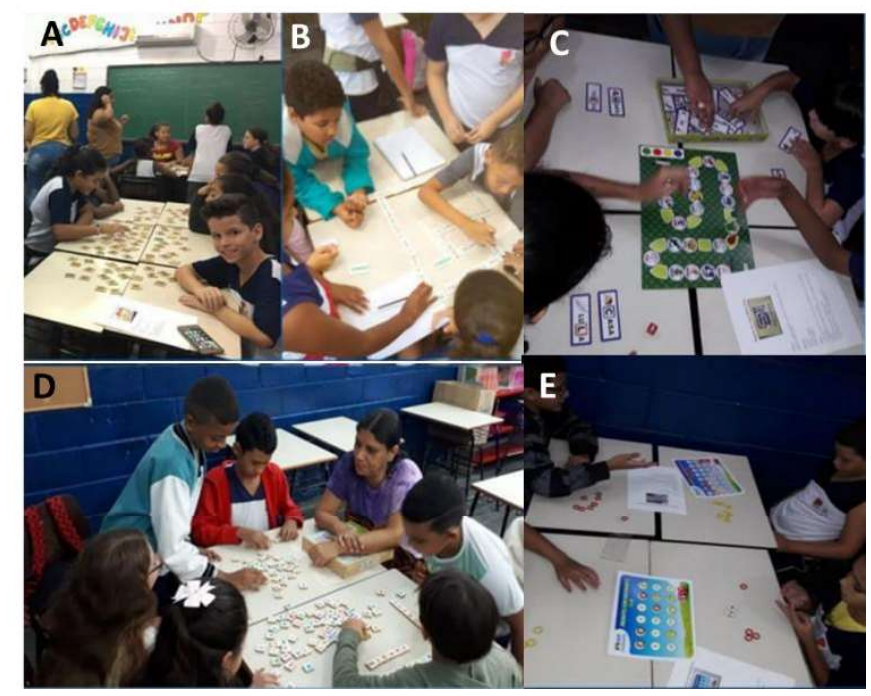

Fonte: Autoria própria*

Ao final da oficina, ressaltou-se a importância do papel de mediação dos bolsistas, pois, estes foram capazes de organizar e aplicar as dinâmicas aos aprendizes, junto aos supervisores, e puderam vivenciar atividades pedagógicas diferenciadas que auxiliaram no processo de ensinoaprendizagem.

"A atividade proposta para os alunos foi executada com êxito, vimos uma grande dinâmica nos alunos do terceiro ano, onde todos entenderam muito bem a proposta e vimos que é possível tratar disciplinas mais tradicionais como o português e matemática com o lúdico e com fluidez. É importante que a escola trate tais atividades com seriedade e traga mais novidades para os alunos trabalharem com essas matérias. É muito difícil tais alunos de uma região periférica terem acesso a

\footnotetext{
2 A-D. Jogos pedagógicos envolvendo formações silábicas e construções de orações; E. Jogo pedagógico envolvendo raciocínio lógico e aritmética.

* Crédito aos licenciandos e a coordenadora de área.
} 
atividades diferenciadas e lúdicas como fizemos, geralmente a aula é engessada onde o professor é obrigado a tratar a disciplina de forma mecânica e repetitiva, incluindo as duas disciplinas trabalhadas" (Relato do licenciando em pedagogia Daniel Fernandes Garcia).

\section{Atividades visando a sustentabilidade}

De modo a promover um trabalho mais integrado e de pertencimento entre os participantes deste subprojeto, as supervisoras bolsistas PIBID propuseram atividades baseadas nos objetivos do projeto e nas habilidades propostas pela Base Nacional Comum Curricular de Ciências da Natureza (BNCC) voltada a cada um dos anos iniciais do ensino fundamental envolvidos, para estabelecer uma relação.

As temáticas variaram desde a discussão da sustentabilidade por meio de atividades envolvendo os 3 Rs (Reduzir, Reutilizar, Reciclar); atividades informativas e dinâmicas sobre o descarte adequado de lixo e processos de reutilização e reciclagem; e, atividades envolvendo a degradação de matéria orgânica por meio da ação de microrganismos decompositores que auxiliam na renovação de nutrientes ambientais, fontes de energia para organismos primários, base das cadeias alimentares.

Ao final deste bloco de atividades, além do desenvolvimento de uma atividade extraclasse, foi realizado um estudo do meio idealizado pelos licenciandos, onde os escolares puderam visitar o Aquário Municipal de Santos (SP), foi promovida uma exposição dos trabalhos desenvolvidos pelas crianças ao longo do projeto, com o auxílio e intervenção dos estudantes PIBID.

\section{Atividades envolvendo organismos decompositores}

Aos alunos do $4^{\circ}$ ano do ensino fundamental foi proposta uma sequência didática com atividades envolvendo microrganismos decompositores, que estão envolvidos com a ciclagem de nutrientes no ambiente, importante fonte energética para os organismos produtores, que são a base das cadeias alimentares. Para tal, foram elaboradas atividades utilizando alimentos como a fruta tomate, para a verificação da degradação da matéria orgânica por meio da 
ação de microrganismos presentes no ambiente (ar e recipiente de armazenamento) (figura 3A).

Outra atividade interessante desenvolvida com a turma foi a produção de meios de cultura (fonte nutritiva a base de extrato de carne e gelatina), fabricados em potes pequenos de vidro reutilizados, para a verificação de crescimento de microrganismos como bactérias e fungos, que convivem com o ser humano. Os alunos utilizaram hastes flexíveis com algodão para a coleta de material: raspados das mãos, boca, sola de sapato, maçaneta de porta e objetos escolares; e então, estes foram semeados nos meios de cultura confeccionados pelos aprendizes com auxílio dos bolsistas PIBID (figura 3B-F).

Figura 3. Microrganismos decompositores ${ }^{3}$

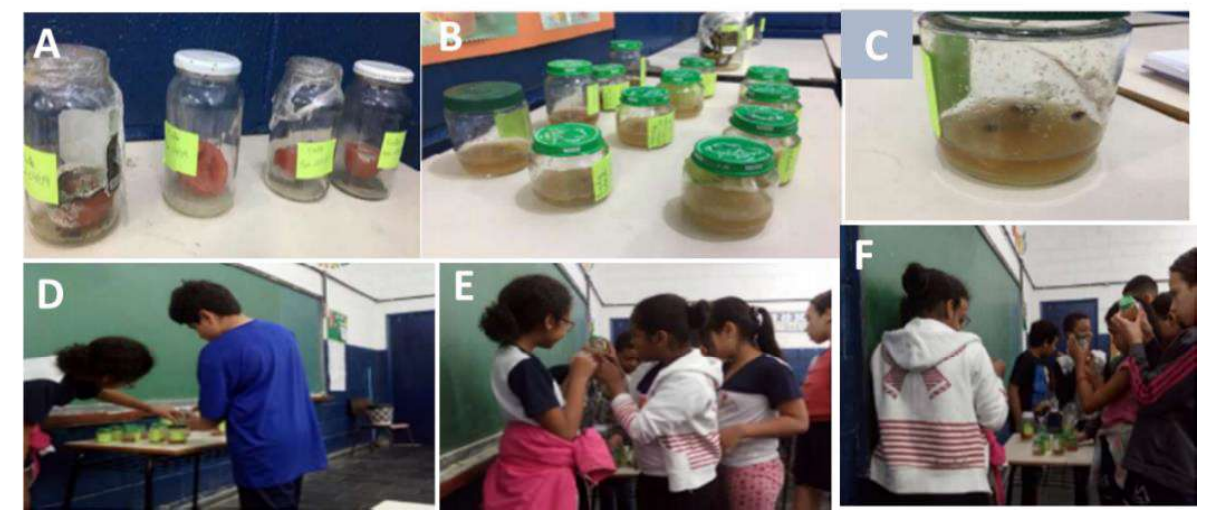

Fonte: Autoria própria*

As propostas e os resultados destas atividades foram interessantes e significativos para todos os envolvidos: escolares, licenciandos e supervisores PIBID, sendo conferidos nos relatos,

"[...] este tema abordou seres que são microscópicos, invisíveis, no qual podemos perceber suas ações e incentivar os alunos a pensar bastante sobre isso [...] o tema aparentou ser difícil, mas se embasando no contexto do aluno é possível

\footnotetext{
${ }^{3}$ A. Fruta tomate cortada inserida em recipientes de vidro não esterilizados e, submetida a ação do ar ambiente ou do recipiente fechado para a verificação e acompanhamento do tempo de decomposição promovida por fungos e bactérias; B. Meios de cultura nutritivos produzidos e armazenados em pequenos recipientes de vidro tampados; $C$. Destaque para o crescimento de organismos no recipiente devido a disponibilidade de nutrientes, proveniente de raspado de sola de sola de sapato; D-F. Envolvimento e interesse demonstrados pelos escolares ao conferir os experimentos realizados.

* Crédito aos licenciandos e a coordenadora de área.
} 
perceber a familiarização fazendo relação com o cotidiano" (Relato da licencianda em pedagogia Layra Verônica Amorim de Paula).

"[...] esse projeto ofertou a possibilidade de tirar conhecimento prévio através de aulas expositivas com conteúdo trabalhado em sala pela professora regente, onde os alunos vivenciaram que os microrganismos são vivos, vivem no nosso meio e não precisamos temer; a experiência do potinho revela-nos que os seres estão nitidamente em tudo que é espaço; quando o professor sai do livro didático e promove uma leitura de mundo, cria contextos que podem favorecer o aprendizado significativo" (Relato do licenciando em pedagogia Edwin de Almeida Diniz de Abreu Souza e Silva).

\section{Atividades sobre descarte de materiais e sua reutilização}

Aos alunos dos $3^{\circ}$ e $5^{\circ}$ ano do ensino fundamental foram propostas atividades pedagógicas envolvendo o descarte correto de materiais como lixo orgânico e àqueles com potencial de reutilização e reciclagem.

Os licenciandos juntamente com seus professores supervisores PIBID planejaram e desenvolveram sequências didáticas com conteúdos e graus de complexidade de acordo com cada ano escolar, entretanto com objetivos muito próximos, visando principalmente a sensibilização para as questões levantadas e a conscientização sobre problemas vivenciados no dia-a-dia, relacionados ao descarte inadequado de lixo, verificado pelo bairro incluindo o entorno escolar, e, que desencadeiam consequências catastróficas sempre que ocorre um período de chuva intensa.

Aos aprendizes do $3^{\circ}$ ano a discussão sobre a sustentabilidade envolveu a exploração temática dos 3 Rs (Reduzir, Reutilizar, Reciclar), e o desenvolvimento de uma oficina de brinquedos com materiais plásticos reutilizados (Figura 4A-B). Aos aprendizes do $5^{\circ}$ ano as atividades desenvolvidas versaram sobre a classificação dos tipos de lixo e a separação de materiais com potencial reciclável e reutilizável, por meio de atividades práticas dinâmicas interativas, coletivas e colaborativas (Figura 4 C-D). 
Figura 4. Reutilizando materiais descartados ${ }^{4}$
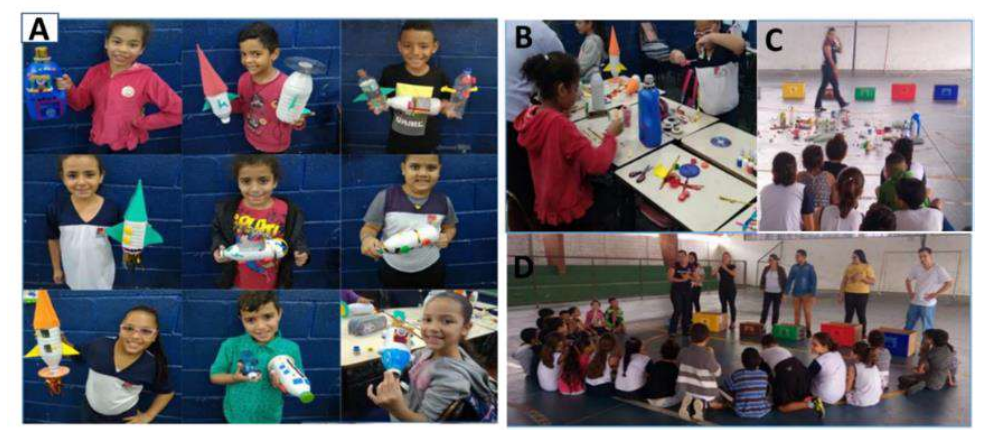

Fonte: Autoria própria*

Os alunos PIBID que participaram deste bloco de atividades relataram que conseguiram cumprir os objetivos propostos atendendo as expectativas acerca da proposição das práticas pedagógicas significativas.

"[...] foi possível observar que o objetivo de sensibilizar e conscientizar os alunos por meio da política dos 3R's foi alcançada, pois, participaram de forma efetiva na construção dos conhecimentos sobre educação ambiental, no que se refere ao destino dos resíduos sólidos e líquidos domiciliares, tendo em vista atitudes e hábitos a serem adotados. Constatou-se que o projeto proporcionou aos alunos a compreensão sobre a importância de consumirmos de maneira consciente e responsável" (Relato da licencianda em pedagogia Patricia Generozo Pataro Tavares).

"[...] por mais que a escola tenha os cestos de lixos para a separação correta, infelizmente não existe a seleção de lixo, nem nas dependências internas (pátio e salas) e nem na cozinha que é o local de maior fluxo de lixo. [...] dessa forma, conseguimos iniciar uma mudança no cotidiano dessas crianças que, agora sabem o porquê do descarte correto dos lixos e as consequências no meio ambiente caso não haja essa separação, contribuindo para melhores ações na escola e consequentemente, iniciando uma grande mudança para o cuidado com o meio ambiente" (Relato da licencianda em pedagogia Leticia do Nascimento Lins).

"As atividades foram importantes para os alunos, mas principalmente para nós bolsistas que através das pesquisas realizadas para podermos preparar as aulas, fomos também sendo conscientizados sobre a importância de termos conhecimento sobre a sustentabilidade e as diversas formas de

4 A. Oficina de brinquedos confeccionados pelos educandos com auxílio dos licenciandos utilizando materiais plásticos descartados; B. Confecção de brinquedos com base em materiais plásticos; C-D.

* Crédito aos licenciandos e a coordenadora de área. 
reaproveitamento e reciclagem" (Relato da licencianda em pedagogia Roseli Alvares de Jesus).

\section{Características e comportamento animal}

Diante dos objetivos propostos sobre habilidades específicas para trabalhar a articulação das linguagens na área de ciências, por meio da comparação entre animais, e, com base em propostas descritas na BNCC de ciências da Natureza, foram elaboradas diferentes atividades aos alunos do $3^{\circ}$ ao $5^{\circ}$ ano do ensino fundamental.

Tais atividades versaram sobre a discussão de diferenças físicas entre os animais, de modo a agrupá-los e classificá-los; modo de locomoção de cada espécie escolhida para ser explorada; diferenças entre os sons emitidos pelos animais; tipos de reprodução, gestação, cuidado com os filhotes; consumo de nutrientes: energia para o funcionamento do organismo dos animais; informações sobre órgãos e sistemas; e, por fim a comparação ao ser humano.

As produções dos alunos foram expostas e apresentadas entre a comunidade escolar de modo a compartilhar os conhecimentos (figura 5 A-D).

Os licenciandos que participaram deste bloco de atividades relataram que as propostas elaboradas juntamente aos aprendizes foram significativas para a percepção da importância dos animais para a natureza e para a vida do ser humano, bem como, despertaram um sentimento de pertencimento ao estabelecerem relações com alguns animais vertebrados abordados, como os domésticos.

\footnotetext{
"Os animais têm uma grande importância no mundo cotidiano das crianças, pela sua presença através de histórias, desenhos animados e por todos os lugares da vida por onde andam; levando a criança a possuir um caráter de identificação de suas vivências pessoais e sociais. O projeto levou à aprendizagem do conhecimento ao respeito com os animais, que são seres vivos importantes para o nosso planeta e para o homem, como componentes da Natureza" (Relato da licencianda em pedagogia Natália Câmara Cabral).
} 
Figura 5. Caracterização dos animais ${ }^{5}$

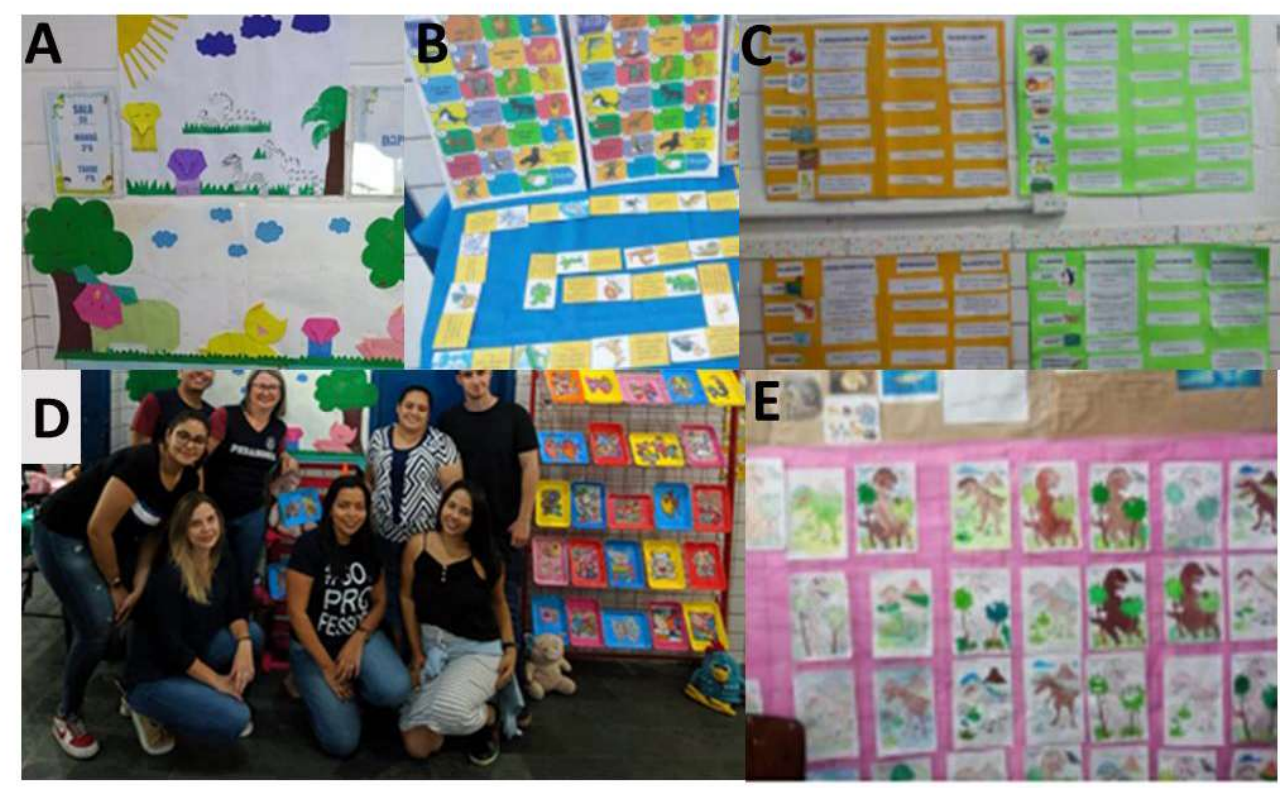

Fonte: Autoria própria*

\section{Estudo do Meio - Visita ao Aquário Municipal de Santos (SP)}

A idealização deste Estudo do Meio partiu dos próprios licenciandos que perceberam a importância de significar e relacionar os conhecimentos obtidos por meio das atividades desenvolvidas na escola durante a execução deste subprojeto PIBID.

A pedido da equipe gestora escolar, a prefeitura municipal de São Vicente (SP), município onde está lotada a escola, cedeu dois ônibus para o transporte de aproximadamente 80 escolares, de modo a realizar esta atividade extraclasse.

Os alunos PIBID se empenharam em conseguir doações de lanches em diferentes comércios, bem como juntaram dinheiro e esforços para a montagem de kits com guloseimas para serem doados as crianças durante a

5 A. Imagens confeccionadas com origami de animais; B. Jogo pedagógico sobre hábitos de vida de diferentes animais vertebrados; C. Atividade envolvendo perguntas sobre as características de classes de animais vertebrados; D. Foto de alguns alunos PIBID com destaque para pinturas de diferentes animais e, confecção de quadros utilizando materiais reutilizados (bandeja de isopor); E. Atividade sobre os dinossauros, suas características e hábitos.

* Crédito aos licenciandos e a coordenadora de área. 
atividade. Ao chegarem no Aquário Municipal de Santos, os lanches foram distribuídos as crianças, que fizeram um grande piquenique antes da visitação pretendida (figura 6 A-E).

Figura 6. Estudo do meio. Aquário Municipal de Santos, SP6



Fonte: Autoria própria*

Os funcionários do Aquário foram muito receptivos e nos proporcionaram uma visita orientada repleta de novos conhecimentos sobre os diferentes animais vertebrados que habitam o local (figura 7A-D). Adicionalmente, foi ministrada uma palestra temática sobre educação ambiental e sustentabilidade (figura 8A-B). Diante das explicações e abordagens temáticas, os alunos puderam relacionar as atividades que desenvolveram ao longo das etapas do projeto PIBID. Por fim, as crianças receberam um gibi com atividades para completar e colorir em casa.

\footnotetext{
${ }^{6}$ A. Chegada e desembarque das crianças e supervisoras Pibid; B-E. Registro fotográfico dos escolares; B. Saída do ônibus; C-D. Piquenique coletivo após o recebimento de lanches. E. Organização dos alunos em fila para a visitação do local.

* Crédito aos licenciandos e a coordenadora de área.
} 
Figura 7. Um pouco do Acervo do Aquário Municipal de Santos, SP7
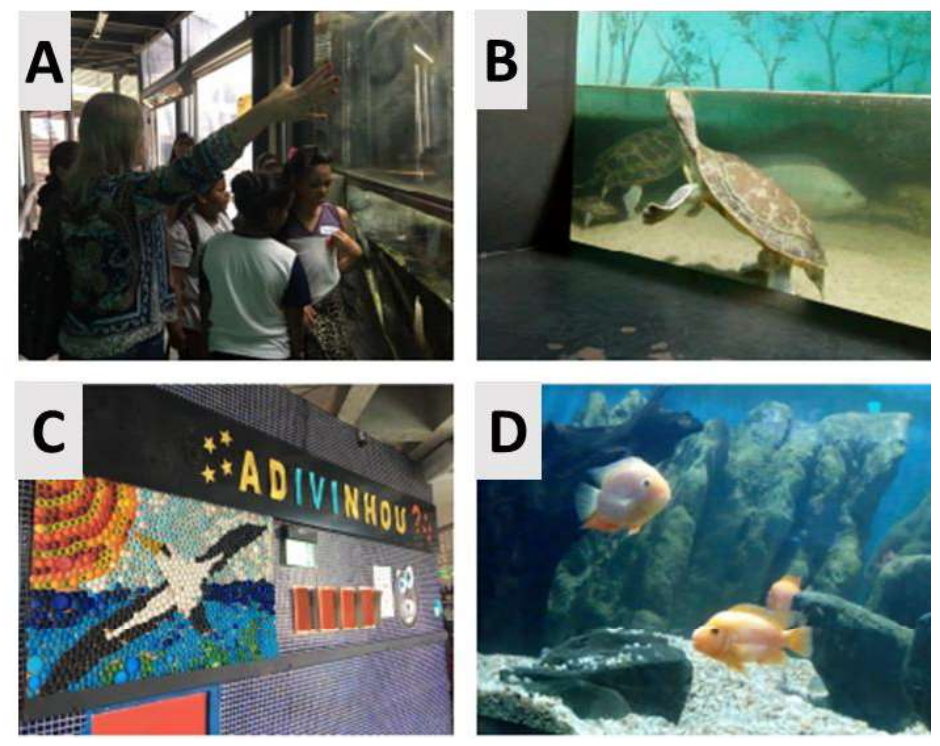

Fonte: Autoria própria*

Figura 8. Palestra sobre sustentabilidade. Importância da preservação ambiental incluindo ambientes marinhos ${ }^{8}$

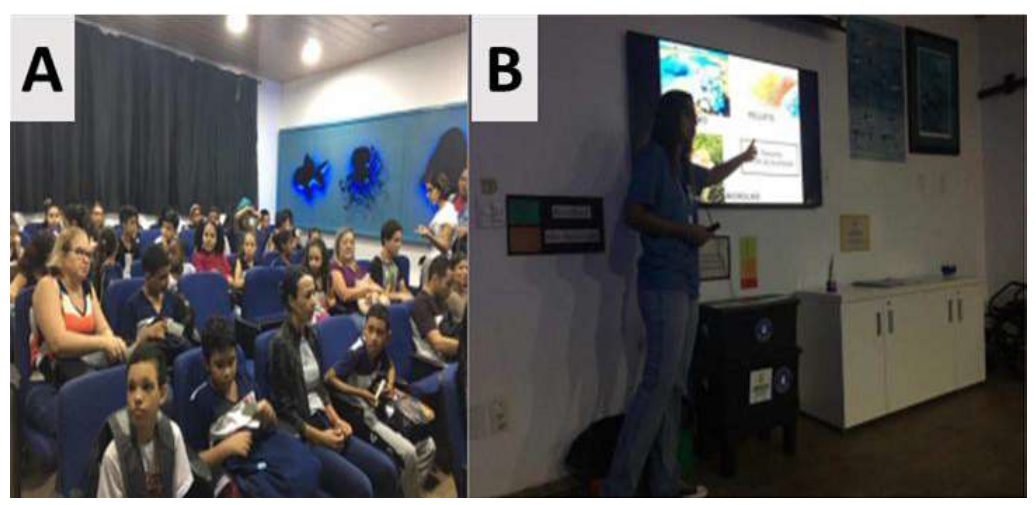

Fonte: Autoria própria*

Esta atividade extraclasse foi realizada com muito carinho e comprometimento de todos os envolvidos, e foi muito gratificante principalmente por compartilhar e vivenciar uma experiência nova para a

${ }^{7}$ A. Explicação aos alunos sobre diferentes peixes de ambiente marinho e suas características; B. Tartaruga marinha; C. Painel confeccionado com tampinhas plásticas de garrafas Pet; imagem de uma ave marinha; sugestão de atividade de sustentabilidade; D. Peixes de ambiente marinho.

${ }^{8}$ A. Alunos no auditório aguardando o início da palestra; B. Palestrante estagiária do Aquário e estudante de Ciências Biológicas explicando sobre a temática.

* Crédito aos licenciandos e a coordenadora de área. 
grande maioria dos escolares. Os alunos bolsistas relataram as suas impressões acerca do Estudo do Meio e identificaram as relações estabelecidas pelos aprendizes, tornando assim, a atividade mais significativa para a formação docente.

"Na visita ao Aquário Municipal de Santos as crianças demostraram um grande interesse e entusiasmo, e conseguiram relacionar o que viram com as atividades propostas na escola. [...] pareceram bastante dispostos $\mathrm{e}$ conscientes ao colocarem todos os ensinamentos em prática. [...] as crianças se transformam em multiplicadores do conhecimento e protetores do meio ambiente em casa e em sua própria comunidade" (Relato da licencianda em pedagogia Cecilia D. Ulrich Regis).

\section{Considerações Finais}

O subprojeto PIBID proposto aos alunos de licenciatura em pedagogia teve como um dos objetivos preparar, incentivar e iniciar os alunos bolsistas à pesquisa científica por meio da construção de material de trabalho e fundamentação teórica para aporte de seus relatórios. Outros objetivos foram alcançados devido ao convívio com as crianças na escola, onde puderam auxiliar e melhorar o letramento dos escolares, despertar o interesse pelo aprendizado, lidar com o improviso no desenvolvimento das tarefas e das temáticas, expressar a linguagem oral, corporal e expressão de ideias e sentimentos que ajudam inclusive a refletir sobre suas próprias ações de forma menos ingênua. Assim, puderam contribuir para a articulação entre teoria e prática necessária à formação dos docentes, elevando a qualidade das ações acadêmicas nos cursos de licenciatura.

Apresentações elaboradas pelos supervisores e pelos estudantes bolsistas, e organizados pelas coordenadoras de área, tanto na escola como na universidade, em momentos planejados distintos, foram qualificadas e transpareceram bons resultados tais como, a superação das dificuldades apresentadas no conjunto de ações junto à escola, onde puderam identificar uma realidade exclusiva do ambiente escolar. Também puderam, na interação, na discussão e na socialização, reconhecer a importância e a responsabilidade do papel de futuro professor. 
O projeto alcançou resultados surpreendentes, qualificados pelos participantes que vivenciaram a realidade escolar, as dificuldades expressivas no contexto educacional e a conscientização de que os licenciados precisam sempre aprimorar seus estudos para que possam compor o quadro acadêmico com valor.

\section{Agradecimentos}

Os autores agradecem à CAPES pelo financiamento do projeto e bolsas e à Universidade Metropolitana de Santos, UNIMES.

\section{Referências}

BRASIL. Conselho Nacional de Educação. Resolução CNE-CP N02/2015. Define as Diretrizes Curriculares Nacionais para a formação inicial em nível superior (cursos de licenciatura, cursos de formação pedagógica para graduados e cursos de segunda licenciatura) e para a formação continuada. Brasília, julho 2015.

BRASIL. Ministério da Educação e do Desporto. Secretaria de Educação Fundamental. Parâmetros curriculares nacionais. Brasília, DF: MEC/SEF,1998.

BRASIL. Ministério da Educação. Base Nacional Comum Curricular. BNCC. Brasília, DF, 2017.

CAPES. Coordenação de aperfeiçoamento de pessoal de nível superior. Programa institucional de bolsa de iniciação à docência, PIBID. Chamada pública para apresentação de propostas. Edital nº 7, 2018.

FREIRE, P. Pedagogia da autonomia: saberes necessários à prática educativa. 54. ed. Rio de Janeiro: Paz e Terra, 2016.

FREIRE, P. Política e Educação: ensaios. 5. ed. São Paulo: Cortez, 2001.

GATTI, B. A. Formação de Professores no Brasil: características e problemas. Adaptações Curriculares/Secretaria de Educação Fundamental. Secretaria de Educação Especial. Brasília: MEC /SEF/SEESP, 1998.

MATOS, M. A. E. Metodologia de projetos, a aprendizagem significativa e a educação ambiental na escola. Ensino, Saúde e Ambiente, v.2, n.1, p 22-29, 2009. 
ROJO, R. Letramentos Múltiplos, Escola e Inclusão Social. São Paulo: Parábola Editorial, 2010.

UNIVERSIDADE Metropolitana de Santos. Projeto Institucional PIBID, 2018.

\section{Sobre os autores}

\section{Elisabeth dos Santos Tavares}

elisabeth.tavares@unimes.br

Doutorado em Educação pela Pontifícia Universidade Católica de São Paulo (2009), Mestrado em Educação pela Pontifícia Universidade Católica de São Paulo (2003) e graduação em Licenciatura em Pedagogia pela Universidade Metropolitana de Santos (1975). Atuação por 25 anos na Educação Básica como professora, diretora de escola, supervisora de ensino e delegada de ensino de Santos. Atualmente é colaborador do Instituto Nacional de Estudos e Pesquisas Educacionais Anísio Teixeira, professor titular do Programa de Mestrado Profissional Práticas Docentes no Ensino Fundamental da Universidade Metropolitana de Santos, membro do Colegiado dos cursos de licenciaturas da Universidade Metropolitana de Santos, membro do Conselho Universitário da Universidade Metropolitana de Santos, coordenadora do núcleo de educação a distância da Universidade Metropolitana de Santos e coordenadora institucional do PIBID. Atuando principalmente nos seguintes temas: Política Educacional, Avaliação de Sistemas, Formação de Professores, Tecnologia e educação.

\section{Elizabeth Magalhães de Oliveira}

elizabeth.oliveira@unimes.br

Possui graduação em Ciências e Licenciatura Plena em Matemática pela Universidade Católica de Santos (1979), mestrado em Educação Matemática pela Universidade Guarulhos (1998) e mestrado em Educação pela Universidade Metodista de São Paulo (2006). Tem experiência na área de Educação, com ênfase em Ensino e Aprendizagem, principalmente nos seguintes temas: educação, metodologia, formação de professor, tecnologias para a educação. Como pesquisadora em Educação Matemática, atua na formação de professores e recuperação de alunos com dificuldades de aprendizagem. Pesquisou e atuou em projetos de Alfabetização Matemática (PNAIC 2013-2016). Atua como professora na UNIMES (Universidade Metropolitana de Santos) (2016-presente) como professora para cursos presenciais e EAD (Educação a Distância), para Licenciatura em Matemática e curso de Física. É professora orientadora de TCC (Trabalho de Conclusão de Curso) para alunos em Licenciatura Matemática e Pós Graduação em Educação Matemática. Trabalhou como professora do IFSP (Instituto Federal de São Paulo) - Campus Cubatão (2018), como professora do Ensino Médio e da Licenciatura em Matemática. Atuou como coordenadora de área pela UNIMES (Universidade Metropolitana de Santos) no PIBID (CAPES) (2018 jan/2020) por meio da integração entre a literatura infanto-juvenil, Artes, Matemática e Ciências e de atividades aplicadas em sala de aula. 


\section{Lais Helena Teixeira Merlin de Andrade}

lais.andrade@unimes.br

Docente de graduação nos cursos de Licenciatura em Ciências Biológicas e em Pedagogia, na modalidade $\mathrm{EaD}$, na Universidade Metropolitana de Santos (Unimes), desde 02/2017. Participou do Projeto PIBID/CAPES - Universidade Metropolitana de Santos (Unimes) como coordenadora de área (maio/2019 jan/2020). Graduada no curso de licenciatura em Pedagogia pelo Centro Universitário FACVEST (2020). Cursou especialização em Formação Pedagógica: Tecnologias para Gestão da Aprendizagem online (Unimes 2019); e, especialização em Educação a Distância (Unimes - 2018). Graduada no curso de licenciatura em Ciências Biológicas pela Universidade Católica de Santos (2001). Mestre em Saúde Coletiva, com ênfase na área de Ambiente e Saúde, pela Universidade Católica de Santos (2008). Doutora em Ciências, com ênfase em desenvolvimento de vacinas, pela Universidade de São Paulo (USP - 2014). Desenvolveu projeto de pós-doutorado no Laboratório de Desenvolvimento de Vacinas do Instituto de Ciências Biomédicas II da Universidade de São Paulo (USP), Departamento de Microbiologia, relacionado à uma imunoterapia vacinal para controlar tumores associados à infecção causada pelo vírus do papiloma humano (HPV) (abr/2014 - dez/2015). Foi técnica de laboratório, das áreas da saúde e biológicas, na Universidade Católica de Santos (2003 - 2008). Possui experiência em Imunologia e em técnicas de Biologia Molecular com ênfase em desenvolvimento de vacinas de subunidades com proteínas recombinantes e, ensaios imunológicos com camundongos; experiência em Parasitologia com ênfase em parasitas de solo arenoso, como larva migrans, e parasitoses intestinais; experiência em Protozoologia com ênfase em amebas de vida-livre; experiência em Microbiologia com análise microbiológica de água; e, experiência em Educação Ambiental. 